\title{
Acúmulo de carboidratos no desenvolvimento de tomateiro tratado com produtos químicos
}

\section{Accumulation of carbohydrates in the development of tomato plants treated with different chemical products}

\author{
Anamaria Ribeiro Pereira Ramos ${ }^{1 *}$; Amanda Cristina Esteves Amaro ${ }^{1}$; \\ Ana Claudia Macedo ${ }^{1}$; Essione Ribeiro Souza ${ }^{1}$; \\ João Domingos Rodrigues ${ }^{2}$; Elizabeth Orika Ono ${ }^{2}$
}

\begin{abstract}
Resumo
Este trabalho teve como objetivo estudar os efeitos fisiológicos da piraclostrobina, boscalida, reguladores vegetais e extrato vegetal no acúmulo de carboidratos durante o desenvolvimento de plantas de tomateiro (Solanum lycopersicum L.), híbrido Giuliana, em condições de ambiente protegido. Os tratamentos estudados foram: T1- testemunha; T2- piraclostrobina $0,2 \mathrm{~g} \mathrm{~L}^{-1}$; T3- boscalida $0,075 \mathrm{~g} \mathrm{~L}^{-1}$, T4- piraclostrobina $0,2 \mathrm{~g} \mathrm{~L}^{-1}+$ boscalida $0,075 \mathrm{~g} \mathrm{~L}^{-1}, \mathrm{~T} 5-\mathrm{IBA}+\mathrm{GA}_{3}+$ cinetina $375 \mathrm{mg} \mathrm{L}^{-1}, \mathrm{~T}^{-}-\mathrm{GA}_{4+7}$ + benzilaminopurina $100 \mathrm{mg} \mathrm{L}^{-1}$ e T7- extrato vegetal $100 \mathrm{mg} \mathrm{L}^{-1}$. A curva de acúmulo de carboidratos foi realizada com cinco amostras, em intervalos de 20 dias entre as avaliações, sendo a $1^{\mathrm{a}}$ avaliação realizada aos 30 dias após o transplantio, no dia da primeira aplicação dos tratamentos. A cada coleta as plantas foram separadas em caule, folha e frutos, nos quais foram avaliados os teores de açúcares solúveis totais, açúcares redutores e sacarose. Também foram avaliados os efeitos dos tratamentos no teor de clorofila e nas trocas gasosas. O delineamento experimental adotado foi inteiramente casualizado, com quatro repetições e seis avaliações destrutivas ao longo do desenvolvimento, sendo uma planta por unidade experimental em cada amostragem. A piraclostrobina e a boscalida aplicados isolados e/ou combinados favoreceram o incremento de carboidratos nas folhas, caules e frutos de tomate 'Giuliana'. Palavras-chave: Solanum lycopersicum L., estrobirulina, piraclostrobina, boscalida, trocas gasosas
\end{abstract}

\begin{abstract}
This work had the purpose to study the physiological effects of pyraclostrobin, boscalid, plant growth regulators and plant extract on the accumulation of carbohydrates during the development of tomato plants (Solanum lycopersicum L.), hybrid Giuliana, in protected environment conditions. The treatments were: T1- control; T2- pyraclostrobin $0.2 \mathrm{~g} \mathrm{~L}^{-1}$; T3- boscalid $0.075 \mathrm{~g} \mathrm{~L}^{-1}$, T4- pyraclostrobin $0.2 \mathrm{~g} \mathrm{~L}^{-1}$ + boscalid $0.075 \mathrm{~g} \mathrm{~L}^{-1}, \mathrm{~T} 5-\mathrm{IBA}+\mathrm{GA}_{3}+$ kinetin $375 \mathrm{mg} \mathrm{L}^{-1}, \mathrm{~T} 6-\mathrm{GA}_{4+7}+$ benzylaminopurine $100 \mathrm{mg}$ $\mathrm{L}^{-1}$ and $\mathrm{T} 7$ - plant extract $100 \mathrm{mg} \mathrm{L}^{-1}$. The carbohydrate accumulation curve was accomplished with 5 samples, at 20-day intervals between evaluations, the $1^{\text {st }}$ evaluation being carried out at 30 days after transplantation, on the day of the first treatment application. At each sampling the plants were separated in stem, leaves and fruits, of which the contents of total soluble sugars, reducing sugars and saccharose were evaluated. The effects of the treatments on chlorophyll content and gas exchanges were also evaluated. The experimental design was completely randomized, with 4 repetitions and 6 destructive evaluations during the development, with 1 plant per experimental unit for each sampling. The pyraclostrobin and boscalid applied in isolation and/or combined favor the increase of carbohydrates in leaves, stems and fruits of tomato hybrid Giuliana.
\end{abstract}

Key words: Solanum lycopersicum L., strobilurin, pyraclostrobin, boscalid, gas exchange

1 Pesquisadores, Dept ${ }^{\circ}$ de Horticultura, Faculdade de Ciências Agronômicas, Universidade Estadual Paulista, UNESP, Botucatu, SP. E-mail: anamaria-ramos@oi.com.br; amandaamaro@uol.com.br; anamacedo85@gmail.com; essione.r@hotmail.com

2 Profs., Dept ${ }^{\circ}$ de Botânica, Instituto de Biociências, UNESP, Botucatu, SP. E-mail: mingo@ibb.unesp.br; eoono@ibb.unesp.br

* Autor para correspondência 


\section{Introdução}

O cultivo de tomateiro em ambiente protegido expandiu-se muito na região Sudeste, principalmente, no Estado de São Paulo. De acordo com Lopes e Stripari (1998), o tomateiro é uma planta muito sensível às condições climáticas e estas, quando desfavoráveis e aliadas a outros fatores, contribuem para seu cultivo, em condições protegidas.

As condições ambientais influenciam $\mathrm{o}$ metabolismo vegetal e determinam as taxas e proporções da fotossíntese e da respiração. Durante o crescimento da planta, aproximadamente $90 \%$ da matéria seca acumulada ao longo do seu crescimento são resultantes da atividade fotossintética (BENINCASA, 2003). A fotossíntese líquida é um indicador da taxa de assimilação de carbono (POPOV et al., 2003) e esses assimilados são utilizados durante o crescimento da planta, convertendo-se em biomassa; e outra parte é oxidada na respiração e serve como fonte de energia para o crescimento e funcionamento dos processos biológicos (POPOV et al., 2003). Além disso, a produtividade vegetal é influenciada por características morfológicas e fisiológicas dos órgãos fotossintetizantes - fonte, e dos órgãos consumidores dos fotoassimilados, conhecidos como drenos (TAIZ; ZEIGER, 2011). Folhas mais velhas, fotossinteticamente ativas, tem a produção de carboidratos maior que o necessário, sendo o excedente dessa produção exportado para os tecidos menos ativos (mais jovens, dreno). Durante o crescimento vegetativo, a maioria dos carboidratos é transportada para as raízes e folhas jovens, enquanto após o florescimento, os carboidratos são direcionados prioritariamente, para os frutos, tubérculos e raízes de reserva (ROITSCH et al., 2003).

De acordo com Hunter, Skrivan e Ruffner (1994) e Palliotti e Cartechini (2001), os teores de glicose, frutose e sacarose, bem como a atividade de enzimas do metabolismo de carboidratos são influenciados por variações sazonais e fenológicas e a expressão gênica é influenciada por uma variedade de fatores intra e extracelulares (TYMOWSKA-LALANNE; KREIS, 1998), como estímulos ambientais, hormonais e fases fenológicas (ROITSCH et al., 2003).

O uso de reguladores vegetais pode promover, inibir ou modificar os processos fisiológicos. Tais substâncias podem alterar diferentes órgãos das plantas, modificando-lhes a morfologia, afetando a produção de matéria seca e, consequentemente, a produtividade (MARTINS; CASTRO, 1997). Segundo Leite, Rosolem e Rodrigues (2003), cada vez mais se tem usado combinações de reguladores vegetais para promover diferentes efeitos fisiológicos em plantas. Casillas et al. (1986) esclarecem que essas substâncias são eficientes quando aplicadas em pequenas doses, com o objetivo de aumentar a produção e as aplicações podem ser realizadas diretamente nas plantas.

Extratos vegetais contendo citocininas foram obtidos em mais de 50 espécies, sendo os níveis mais altos registrados em tecidos onde ocorre a divisão celular (TAIZ; ZEIGER, 2011). Um dos produtos utilizados nesse trabalho é um estimulante vegetal composto de extratos de Agave (Yucca schidigera) e micronutrientes minerais, com ação semelhante às citocininas e de nome comercial Crop $\operatorname{Set}^{\mathrm{O}}$ (SOUZA LEÃO; SILVA; SILVA, 2005).

Além dos extratos vegetais, os fungicidas com ação fisiológica, como as estrobilurinas, vem sendo utilizados em várias culturas, como tomate (RAMOS, 2013), pepino (AMARO, 2011) e melão rendilhado (MACEDO, 2012) por promoverem alterações no metabolismo e crescimento do vegetal. Esse efeito fisiológico observado é resultante do aumento da fotossíntese líquida, pois reduz temporariamente a respiração das plantas, o que provoca menor perda de carbono, gerando mais energia para a planta (KÖEHLE et al., 1994). Também inibe a síntese de etileno, por meio da redução da atividade da enzima ácido aminociclopropano-carboxílico sintase (ACC-sintase). Dessa forma, reduzem a 
perda de clorofila que ocorre durante a senescência, mantendo as folhas verdes, e aumenta a atividade da enzima nitrato-redutase (KÖEHLE et al., 1994; YPEMA; GOLD, 1999; VENÂNCIO et al., 2003).

O boscalida é um fungicida sistêmico pertencente à classe das carboxamidas, que inibe o transporte de elétrons na mitocôndria no complexo II, o qual é necessário na fosforilação oxidativa. O complexo II, além de participar da produção de energia na célula, também atua na junção onde os componentes do ciclo do ácido tricarboxílico tornam-se precursores para aminoácidos e lipídios. Funciona inibindo a succinato ubiquinona redutase na mitocôndria (AVENOT; MICHAILIDES, 2010).

Assim, o objetivo deste trabalho foi estudar o acúmulo de carboidratos promovido pelas piraclostrobina, boscalida, reguladores vegetais e extrato vegetal em plantas de tomateiro 'Giuliana' cultivadas em condições de ambiente protegido, pelas medidas de trocas gasosas.

\section{Material e Métodos}

O experimento foi conduzido no período de novembro de 2009 a março de 2010, na área experimental da Fazenda de Ensino, Pesquisa e Produção de São Manuel, município de São Manuel - SP, pertencente à Faculdade de Ciências Agronômicas, Câmpus de Botucatu, da Universidade Estadual Paulista - UNESP. As coordenadas geográficas são $22^{\circ} 44^{\prime} \mathrm{S}$ de latitude, $47^{\circ} 34^{\prime} \mathrm{W}$ de longitude e 750 metros de altitude. O clima é do tipo mesotérmico subtropical úmido com estiagem na época de inverno (PEEL; FINLAYSON; MCMAHON, 2007).

$\mathrm{O}$ ambiente protegido tinha cobertura de filme de polietileno de baixa densidade de $150 \mu \mathrm{m}$ aditivado e com as laterais fechadas com tela de sombreamento de $75 \%$ e o solo do local é classificado como Latossolo Vermelho Amarelo fase arenosa (CAMARGO; KLAMT; KAUFFMAN, 1987; EMBRAPA, 2006). Nesse local, foram construídos oito canteiros, com altura de $0,20 \mathrm{~m}$ acima do nível do terreno. Em cada canteiro foi instalada uma linha de irrigação por gotejamento com emissores posicionados a cada $30 \mathrm{~cm}$, com vazão de $5 \mathrm{~L}$ $\mathrm{h}^{-1} \mathrm{~m}^{-1} \mathrm{e}$ a frequência diária de uma hora e meia, com irrigações diárias. A correção, adubação do solo e fertirrigação foram realizadas com base na análise química do solo, retirado do local onde foi instalado o experimento, sendo a fertirrigação realizada semanalmente.

As mudas de tomateiro 'Giuliana' foram preparadas em bandejas de poliestireno expandido com 128 células preenchidas com substrato comercial Carolina Soil ${ }^{\circledR}$ II composto de turfa de Sphagno, vermiculita expandida, resíduo orgânico agroindustrial classe A, calcário dolomítico, gesso agrícola e traços de fertilizantes NPK, pH 5,5 $\pm 0,5$, CE $0,4 \pm 0,3 \mathrm{mScm}^{-1}$ e densidade $155 \mathrm{~kg} \mathrm{~m}^{-3}$, colocando-se uma semente por célula. As mudas foram transplantadas com quatro folhas definitivas para os canteiros, 36 dias após a semeadura, utilizando-se espaçamento de $1,0 \times 0,5 \mathrm{~m}$, resultando numa densidade de 20.000 plantas ha ${ }^{-1}$. Após o transplantio, realizou-se a primeira irrigação com duração de 30 minutos para a adaptação das plantas ao novo ambiente.

As plantas foram conduzidas com uma haste ao longo do ciclo, com uma planta por cova e tutoradas com bambu, individualmente, no período de novembro de 2009 a março de 2010.

A primeira aplicação dos tratamentos foi realizada aos 30 dias após o transplante das mudas; no início do florescimento, e as demais, a cada 20 dias, totalizando seis aplicações. As aplicações foram via foliar realizadas com o uso de pulverizador manual de $\mathrm{CO}_{2}$ pressurizado, com pressão de $2 \mathrm{kgf} \mathrm{cm}^{-2} \mathrm{e}$ vazão de $0,2 \mathrm{~L} \mathrm{~min}^{-1}$, utilizando-se cortina plástica entre os tratamentos para evitar a deriva.

Os tratamentos avaliados foram: T1- testemunha; T2- piraclostrobina 0,2 $\mathrm{g} \mathrm{L}^{-1}$; T3- boscalida 0,075 g $\mathrm{L}^{-1}$; T4- piraclostrobina $0,2 \mathrm{~g} \mathrm{~L}^{-1}+$ boscalida 0,075 $\mathrm{g} \mathrm{L}^{-1}$; T5- IBA + $\mathrm{GA}_{3}+$ cinetina $375 \mathrm{mg} \mathrm{L}^{-1}$; T6- 
$\mathrm{GA}_{4+7}+$ benzilaminopurina $100 \mathrm{mg} \mathrm{L}^{-1}$ e T7- extrato vegetal $100 \mathrm{mg} \mathrm{L}^{-1}$. Em todos os tratamentos foi adicionado óleo vegetal (Natural'óleo ${ }^{\circledR}$ ) a 0,5\% para evitar as perdas por hidrólise, evaporação, deriva, lavagem e fotodecomposição.

Como fonte de boscalida utilizou-se o produto comercial Cantus $^{\circledR}$, contendo $500 \mathrm{~g} \mathrm{~kg}^{-1}$ do p.a. e para a piraclostrobina, o produto comercial Comet巴, contendo $250 \mathrm{~g} \mathrm{~L}^{-1}$ do p.a.. Como fonte da mistura de ácido indolilbutírico (IBA- auxina), $\mathrm{GA}_{3}$ (giberelina) e cinetina (citocinina) utilizou-se o produto comercial Stimulate ${ }^{\hat{a}}$, contendo $90 \mathrm{mg} \mathrm{L}^{-1}$ de cinetina (Kt), $50 \mathrm{mg} \mathrm{L}^{-1}$ de IBA e $50 \mathrm{mg} \mathrm{L}^{-1}$ de $\mathrm{GA}_{3}$ por litro do produto. Como fonte da mistura de benzilaminopurina (citocinina) e $\mathrm{GA}_{4+7}$ (giberelina), o produto comercial Promalin ${ }^{\circledR}$, contendo $1,8 \%$ de $\mathrm{GA}_{4+7}$ e $1,8 \%$ de benzilaminopurina (BAP). Como fonte do extrato vegetal, utilizou-se o produto comercial Crop Set ${ }^{\mathrm{O}}$, contendo micronutrientes: 1\% de cobre, $4,69 \%$ de enxofre, $2,5 \%$ de ferro e $3 \%$ de manganês da Improcop do Brasil Ltda.

O delineamento experimental foi inteiramente casualizado, com sete tratamentos e quatro repetições. Para a avaliação de acúmulo de carboidratos foram realizadas cinco avaliações destrutivas ao longo do desenvolvimento, a cada 20 dias, sendo a primeira realizada aos 50 dias após o transplantio. Foi utilizada uma planta por tratamento, por repetição, em cada amostragem.

A cada coleta as plantas foram separadas em caule, folha e frutos, acondicionadas em sacos de papel e esse material levado para secar em estufa de circulação forçada de ar a $60^{\circ} \mathrm{C}$, até atingirem massa constante. Após a secagem, o material foi moído, homegeneizado, acondicionado em frascos de plástico transparente, hermeticamente fechados e guardados em câmara seca para posterior avaliação.

Os teores de açúcares redutores foram quantificados pelo método dinitrosalicilato (DNS), que quantifica glicose, frutose e manose nos tecidos vegetais (MILLER, 1959); o teor de açúcares solúveis totais foi quantificado pelo método da antrona (MORRIS, 1948; YEMM; WILLIS, 1954)

e a sacarose, por meio da reação com antrona fria (PASSOS, 1996).

As avaliações de trocas gasosas foram realizadas utilizando-se equipamento com sistema aberto de fotossíntese, com analisador de $\mathrm{CO}_{2}$ e vapor d'água, por radiação infravermelha (Infra Red Gas Analyser - IRGA, modelo LI-6400, Li-Cor). Essas medidas foram realizadas das 9:00 às 11:00 h em dia ensolarado em folhas completamente expandidas. As medidas foram feitas aos 45, 96 e 124 dias após o transplante selecionando-se quatro plantas de cada tratamento. A concentração de $\mathrm{CO}_{2}$ de referência utilizada durante as avaliações foi a do ambiente, a qual variou de 380 a $400 \mu \mathrm{mol} \mathrm{CO} \mathrm{mol}^{-1}$ de ar.

A fim de homogeneizar as repetições, a densidade de fluxo de fótons fotossinteticamente ativos (DFFFA) foi gerada por um diodo emissor de luz acoplado à câmara de fotossíntese, padronizando a luminosidade que estava presente no ambiente em cada período de avaliação, para que todas as plantas estivessem sob as mesmas condições de luz, utilizando $1500 \mu \mathrm{mol} \mathrm{m} \mathrm{m}^{-2} \mathrm{~s}^{-1}$, baseado em curva de luz realizada previamente. Durante as avaliações foram coletados os dados de temperatura e umidade relativa do ar utilizando o próprio medidor de trocas gasosas.

As características de trocas gasosas analisadas foram: taxa de assimilação de $\mathrm{CO}_{2}\left(A, \mu \mathrm{molCO}_{2} \mathrm{~m}^{-2} \mathrm{~s}\right.$ $\left.{ }^{1}\right)$, taxa de transpiração $\left(E, \mathrm{mmol}\right.$ vapor d'água $\mathrm{m}^{-2} \mathrm{~s}$ $\left.{ }^{1}\right)$ e condutância estomática $\left(g s, \mathrm{~mol} \mathrm{~m}^{-2} \mathrm{~s}^{-1}\right)$. Essas características foram calculadas pelo programa de análise de dados do equipamento medidor de fotossíntese, que utiliza a equação geral de trocas gasosas de Von Caemmerer e Farquhar (1981).

A eficiência do uso da água $\left(E U A, \mu \mathrm{mol} \mathrm{CO}_{2}\right.$ $\left(\mathrm{mmol} \mathrm{H}_{2} \mathrm{O}\right)^{-1}$ ) foi determinada através da relação entre assimilação de $\mathrm{CO}_{2}$ e taxa de transpiração e a eficiência de carboxilação $(\mathrm{A} / \mathrm{C} i)$ foi determinada através da relação entre taxa de assimilação de $\mathrm{CO}_{2}$ e concentração interna de $\mathrm{CO}_{2}$ na folha.

Também foi avaliado o teor de clorofila em 
folhas completamente expandidas, utilizando-se clorofilômetro SPAD da Minolta em unidades Spad. Os resultados obtidos para teor de clorofila foram submetidos à análise de variância e suas médias comparadas pelo teste Tukey a 5\% de probabilidade. Os teores de açúcares foram submetidas à análise fatorial 7 × 3 (7 tratamentos e 3 órgãos vegetais) e suas médias comparadas pelo teste Tukey a 5\% de probabilidade.

\section{Resultados e Discussão}

Verificou-se que, aos 45 DAT (início da frutificação), as plantas tratadas com a mistura de piraclostrobina + boscalida apresentaram folhas com maior teor de clorofila, a qual se manteve até aos 96 DAT (pico da colheita), porém não diferindo estatisticamente dos tratamentos com boscalida, piraclostrobina e a testemunha, mostrando que tanto a mistura, como esses produtos isolados, retardam o amarelecimento das folhas, atrasando sua senescência e prolongando a atividade fotossintética (Tabela 1). Amaro (2011) verificou que a mistura de piraclostrobina + boscalida e boscalida aplicado isoladamente retardaram o amarelecimento das folhas em pepino japonês (Cucumis sativus) enxertado e não enxertado.

Tabela 1. Teor de clorofila (índice Spad) em folhas de plantas de tomate 'Giuliana' cultivadas sob cultivo protegido e tratadas com diferentes produtos químicos, com efeitos fisiológicos aos 45 e 96 dias após o transplantio (DAT). Botucatu (SP), 2009/2010.

\begin{tabular}{lcc}
\hline Tratamentos & $45 \mathrm{DAT}$ & $96 \mathrm{DAT}$ \\
\hline Testemunha & $46,20 \mathrm{ab}$ & $54,91 \mathrm{Ab}$ \\
Piraclostrobina & $45,26 \mathrm{ab}$ & $52,33 \mathrm{Ab}$ \\
Boscalida & $47,09 \mathrm{ab}$ & $53,48 \mathrm{Ab}$ \\
piraclostrobina + boscalida & $48,48 \mathrm{a}$ & $58,73 \mathrm{~A}$ \\
$\mathrm{IBA}+\mathrm{GA}_{3}+$ cinetina & $43,79 \mathrm{~b}$ & $51,83 \mathrm{~B}$ \\
$\mathrm{GA}_{4+7}+$ benzilaminopurina & $44,16 \mathrm{~b}$ & $43,84 \mathrm{C}$ \\
extrato vegetal & $45,95 \mathrm{~b}$ & $52,26 \mathrm{Ab}$ \\
$\mathrm{CV}(\%)$ & 3,32 & 5,72 \\
\hline
\end{tabular}

Médias seguidas de mesma letra nas colunas, não diferem significativamente entre si pelo teste Tukey a 5\% de probabilidade. 45 DAT= início da frutificação; 96 DAT= pico da colheita.

Fonte: Elaboração dos autores.

Analisando os teores de açúcares totais (AT) aos 50 DAT (Tabela 2) observa-se que não houve diferença estatística entre os tratamentos, quando analisado os teores nas folhas. No caule, o tratamento com piraclostrobina propiciou a maior concentração desses açúcares em relação aos demais tratamentos; porém, não diferiu do tratamento com boscalida. Nos frutos, os tratamentos com boscalida e IBA $+\mathrm{GA}_{3}+$ cinetina e $\mathrm{GA}_{4+7}+$ benzilaminopurina proporcionaram concentracões de AT superiores aos demais tratamentos, indicando translocação efetiva dos fotoassimilados para os frutos. De maneira geral, a citocinina promove a síntese de proteínas e de carboidratos (CASTRO; VIEIRA, 2001; COLL et al., 2001; DAVIES, 2004). Essas substâncias, segundo Davies (2004) e Salisbury e Ross (1994), também estão envolvidas no desenvolvimento de organelas, na atividade enzimática, na abertura estomática, no desenvolvimento de frutos e na hidrólise de reservas de sementes.

Para os açúcares redutores (AR) (Tabela 2) não houve diferença significativa quando analisados os teores nas folhas e no caule; porém, nos frutos tratados com IBA $+\mathrm{GA}_{3}+$ cinetina e $\mathrm{GA}_{4+7}+$ benzilaminopurina os teores de $\mathrm{AR}$ foram superiores. Para os teores de sacarose (SAC) nos frutos e no caule não houve diferença entre os tratamentos. Nas folhas, porém, o extrato vegetal foi o tratamento 
em que se registrou o menor acúmulo desse açúcar, diferindo dos demais tratamentos.

Em todos os tratamentos, a concentração de açúcares totais e redutores nos frutos foi estatisticamente superior às folhas e ao caule, mais uma vez, mostrando que os tratamentos foram efetivos na maior translocação de açúcares para o principal dreno nesse estádio de desenvolvimento da planta. Apenas no tratamento com $\mathrm{GA}_{4+7}+$ benzilaminopurina, os teores de AT foram superiores nas folhas, quando comparadas com o caule, porém esse foi o tratamento que apresentou a menor concentração de AR no caule. A concentração de sacarose foi estatisticamente superior no caule, com exceção do tratamento testemunha, onde não houve diferença em relação ao órgão vegetal analisado (Tabela 2). O principal açúcar transportadopelo floema é a sacarsose, assim, a maior concentração de sacarose nesse órgão pode ser explicada por esse fato.

Com relação à taxa de assimilação de $\mathrm{CO}_{2}(A)$, aos 45 DAT (Figura 1), plantas tratadas com boscalida e com a mistura de piraclostrobina + boscalida apresentaram os melhores resultados, concordando com os resultados obtidos por Amaro et al. (2009), em plantas de pepino (Cucumis sativus).

Figura 1. Taxa de assimilação de $\mathrm{CO}_{2}\left(A, \mu \mathrm{mol} \mathrm{CO} \mathrm{m}^{-2} \mathrm{~s}^{-1}\right)$, Condutância estomática $\left(g s, \mathrm{~mol} \mathrm{~m}^{-2} \mathrm{~s}^{-1}\right)$, Transpiração $(E$, $\mathrm{mmol}$ vapor d'água $\left.\mathrm{m}^{-2} \mathrm{~s}^{-1}\right)$, Eficiência do uso da água $\left(E U A-A / E, \mu \mathrm{mol} \mathrm{CO}_{2}\left(\mathrm{mmol} \mathrm{H}_{2} \mathrm{O}\right)\right)$ e Eficiência de carboxilação em folhas de plantas de tomate cv. Giuliana em cultivo protegido e tratadas com diferentes produtos químicos com efeitos fisiológicos aos 45 DAT, Botucatu (SP), 2009/2010.

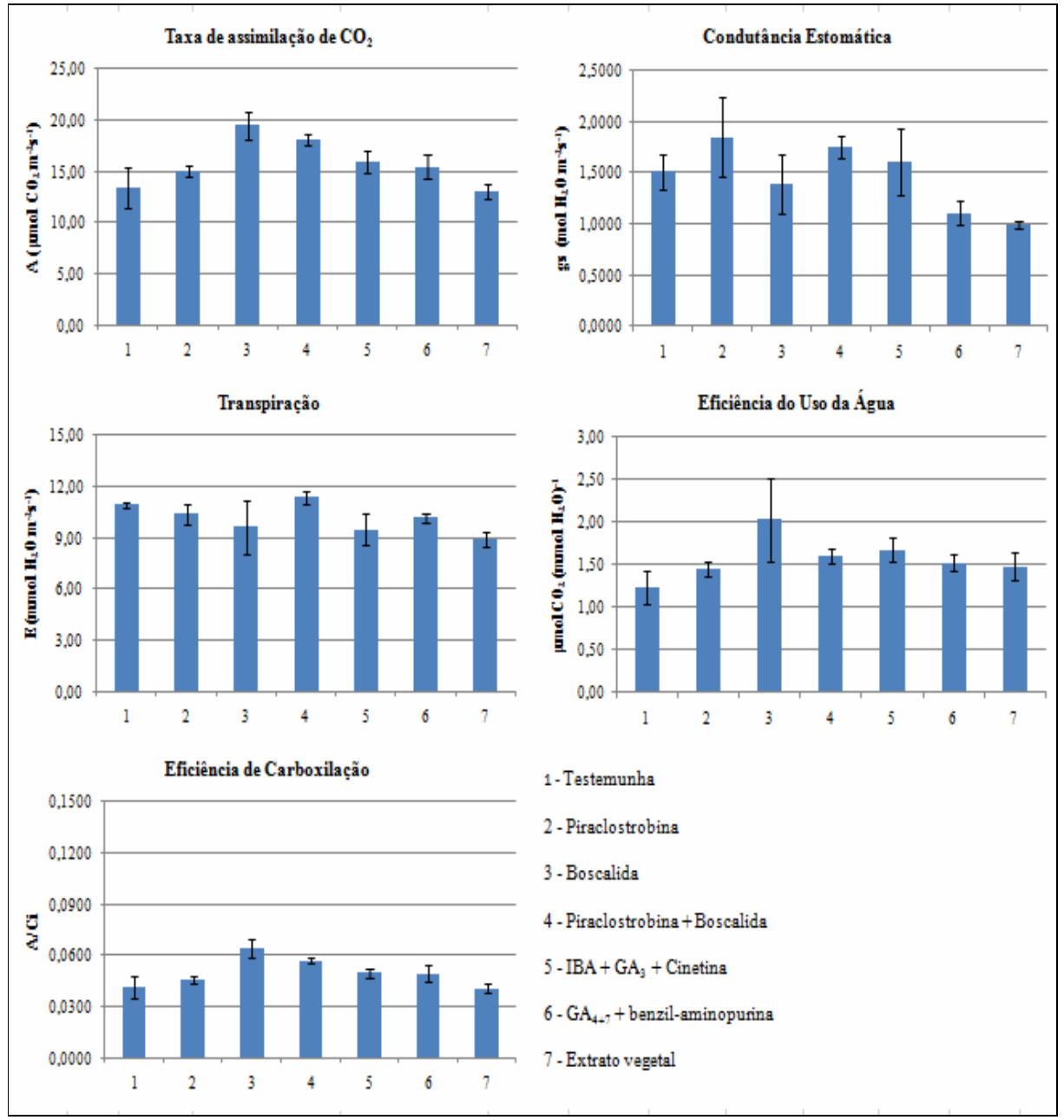

Fonte: Elaboração dos autores. 
Plantas tratadas somente com o boscalida apresentaram alta taxa de assimilação de $\mathrm{CO}_{2}$, mas baixa taxa de transpiração e baixos valores de condutância estomática, o que evidencia a sua alta eficiência do uso da água. A importância dessa eficiência demonstra a capacidade da planta assimilar o $\mathrm{CO}_{2}$ com o mínimo de perda de água durante esse processo, o que acarreta na maior economia de água pelas plantas e maior síntese de fotoassimilados. Isso pode ser comprovado pelo aumento da eficiência de carboxilação (Figura 1).

$\mathrm{O}$ tratamento com extrato vegetal não influenciou positivamente na taxa de assimilação de $\mathrm{CO}_{2}$, sendo similar à testemunha; entretanto, apresentou baixa condutância estomática, o que demonstra que os estômatos estavam mais fechados que nos demais tratamentos, com menor eficiência de carboxilação e acúmulo de carboidratos (Figura1).

As plantas tratadas com a mistura de piraclostrobina + boscalida também apresentaram a maior taxa de transpiração, provocada pela alta condutância estomática, o que gerou uma baixa eficiência do uso da água. Entretanto, apresentaram boa eficiência de carboxilação, que não resultou em maior acúmulo de carboidratos na planta (Figura1).

A concentração de açúcares totais nas folhas, aos 70 DAT (Tabela 3), foi maior nas plantas tratadas com $\mathrm{GA}_{4+7}+$ benzilaminopurina, seguida de piraclostrobina, extrato vegetal e a mistura de piraclostrobina + boscalida, enquanto que no caule o melhor tratamento foi à mistura de piraclostrobina e boscalida, porém não diferiu dos tratamentos testemunha, piraclostrobina, boscalida e extrato vegetal. No entanto, os tratamentos com piraclostrobina, $\mathrm{GA}_{4+7}+$ benzilaminopurina, boscalida, extrato vegetal e testemunha influenciaram positivamente nos teores de açúcares totais no fruto. Coulombe e Paquin (1959), estudando a fotossíntese e a transpiração mediante a aplicação de ácido giberélico, observaram aumento nas taxas, após a pulverização de $100 \mathrm{mg} \mathrm{L}^{-1}$ de $\mathrm{GA}_{3}$ em plantas de tomate. Haber e Tolbert (1957) não encontraram diferenças na fixação de $\mathrm{CO}_{2}$ em aveia (Avena sativa L.), independente da concentração, que variou entre 0 e $1000 \mathrm{mg} \mathrm{L}^{-1}$. Conforme Matsumoto (2000), as giberelinas influenciam várias ações fisiológicas de genes em plantas; entre elas, nas atividades de enzimas hidrolíticas tais como a $\alpha$-amilase, a carboxipeptidase e a cisteína-proteinase. A $\alpha$-amilase atua sobre o amido e hidrolisa as ligações glicosídicas dos tecidos de reserva, produzindo substâncias como a glicose.

No caule e nas folhas não houve diferença estatística entre os tratamentos quando analisadas as concentrações de açúcares redutores. Nos frutos, o tratamento com $\mathrm{GA}_{4+7}+$ benzilaminopurina mostrou maior incremento no teor desses açúcares, porém não diferindo estatisticamente dos tratamentos com piraclostrobina, com a mistura de piraclostrobina e boscalida, IBA $+\mathrm{GA}_{3}+$ cinetina, extrato vegetal e a testemunha. Em relação aos órgãos analisados, os frutos acumularam estatisticamente mais açúcares redutores do que as folhas e os caules, possivelmente, posteriormente, esses açúcares serão consumidos para o crescimento dos frutos.

Quando avaliado o teor de sacarose nas folhas e nos frutos, estatisticamente, não houve diferenças. Contudo, este efeito não foi observado no caule, visto que a testemunha e a mistura de piraclostrobina e boscalida foram os tratamentos que apresentaram as maiores médias, diferindo estatisticamente dos demais. Segundo Kohatsu (2007), a aplicação de IBA, cinetina e a mistura dos reguladores vegetais $\mathrm{GA}_{3}+\mathrm{IBA}+$ cinetina influenciaram na taxa fotossintética de plantas de melão rendilhado (Cucumis melo var. reticulatus).

Aos 90 DAT (Tabela 4), a concentração de açúcares totais não diferiu entre os tratamentos para folhas e frutos. Entretanto, no caule, houve diferença significativa no tratamento com piraclostrobina e com a mistura deste com boscalida. Para os teores de açúcares redutores apenas o tratamento com $\mathrm{GA}_{4+7}+$ benzilaminopurina mostrou aumento significativo no teor destes açúcares nos frutos, os demais não apresentaram diferença. Analisado o teor de sacarose, a mistura de piraclostrobina e boscalida aumentou a concentração desse açúcar no caule. 


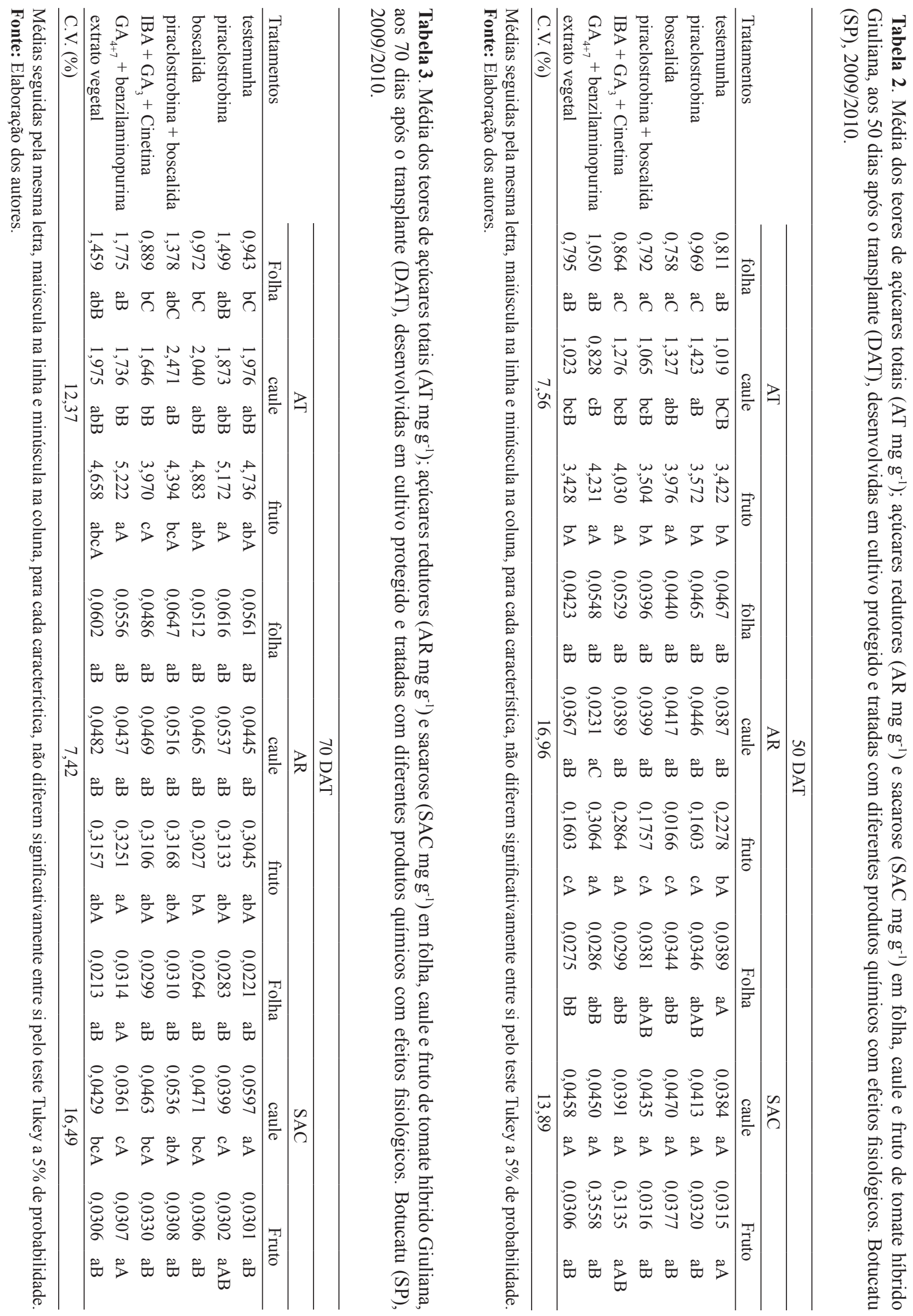


O açúcar em abundância promove o crescimento e o armazenamento de carboidratos nos drenos e quando a taxa de fotossíntese é alta, ocorre o acúmulo de açúcares totais nas folhas (TAIZ; ZEIGER, 2011). As giberelinas presentes em alguns tratamentos regulam vários aspectos associados ao crescimento das plantas, o que justifica o resultado encontrado.

Com relação aos órgãos vegetais analisados, os frutos acumularam mais açúcares totais e redutores. No caule houve maior concentração de sacarose, porém só houve diferença dos frutos nos tratamentos com boscalida, a mistura de piraclostrobina e boscalida e o extrato vegetal.

Quando avaliada a concentração de açúcares totais aos 110 DAT (Tabela 5), observa-se que não houve diferenças entre os tratamentos. Nos teores de açúcares redutores, apenas o tratamento com boscalida nos frutos mostrou aumento, porém não diferindo da testemunha. As plantas tratadas com $\mathrm{GA}_{4+7}+$ benzilaminopurina apresentaram maiores teores de sacarose na folha. Seguindo a tendência das outras coletas, os frutos acumularam mais açúcares totais e redutores e o caule mais sacarose.

Para os açúcares totais avaliados nas folhas, aos 130 DAT (Tabela 6), o tratamento com a mistura de piraclostrobina + boscalida, $\mathrm{GA}_{4+7}+$ benzilaminopurina e extrato vegetal apresentaram os maiores teores desses açúcares. O mesmo não ocorreu no caule, no qual o tratamento com piraclostrobina se destacou. Já no fruto, o melhor tratamento foi à mistura de piraclostrobina e boscalida. Nos teores de açúcares redutores nas folhas e no caule não foi evidenciada diferenças, mas os tratamentos com $\mathrm{GA}_{4+7}+$ benzilaminopurina e a mistura de piraclostrobina + boscalida apresentaram maiores teores desses açúcares no fruto. Avaliando as concentrações de sacarose nas folhas, as plantas apresentaram maiores teores nos tratamentos com IBA $+\mathrm{GA}_{3}+$ cinetina e nos frutos o melhor tratamento foi com $\mathrm{GA}_{4+7}+$ benzilaminopurina, no caule não foram evidenciadas diferenças entre os tratamentos.

$\mathrm{O}$ tratamento com IBA $+\mathrm{GA}_{3}+$ cinetina (Figura 2) apresentou a maior taxa de assimilação de $\mathrm{CO}_{2}$. Entretanto, a maior eficiência de carboxilação e eficiência do uso da água foi observada no tratamento com piraclostrobina. Garbelini (2009), estudando a aplicação de reguladores vegetais em macadâmia (Macadamia integrifolia Maiden \& Betche), observou que a concentração interna de $\mathrm{CO}_{2}$ dentro da câmara subestomática $(\mathrm{C} i)$ não foi afetada pelos tratamentos e quando comparadas a transpiração com a condutância estomática e a taxa de assimilação de $\mathrm{CO}_{2}$, os maiores valores de trocas gasosas foram encontrados nas plantas tratadas com $\mathrm{IBA}+\mathrm{GA}_{3}+$ cinetina $\left(5,0 \mathrm{~mL} \mathrm{~L}^{-1} \mathrm{em} 2\right.$ aplicações $)$. Esses resultados estão de acordo com os registros de Larcher (2006), que descreve que, por meio da regulação estomática, a planta é capaz de modular as taxas de transpiração de acordo com seu balanço hídrico. Taiz e Zeiger (2011) também relatam que mudanças na resistência estomática são importantes para a regulação da perda de água pelas plantas e para o controle da taxa de absorção de $\mathrm{CO}_{2}$, necessária à fotossíntese. $\mathrm{O}$ aumento na biomassa não depende somente da assimilação de $\mathrm{CO}_{2}$, mas do balanço hormonal e do padrão específico de cada planta (LARCHER, 2006). 


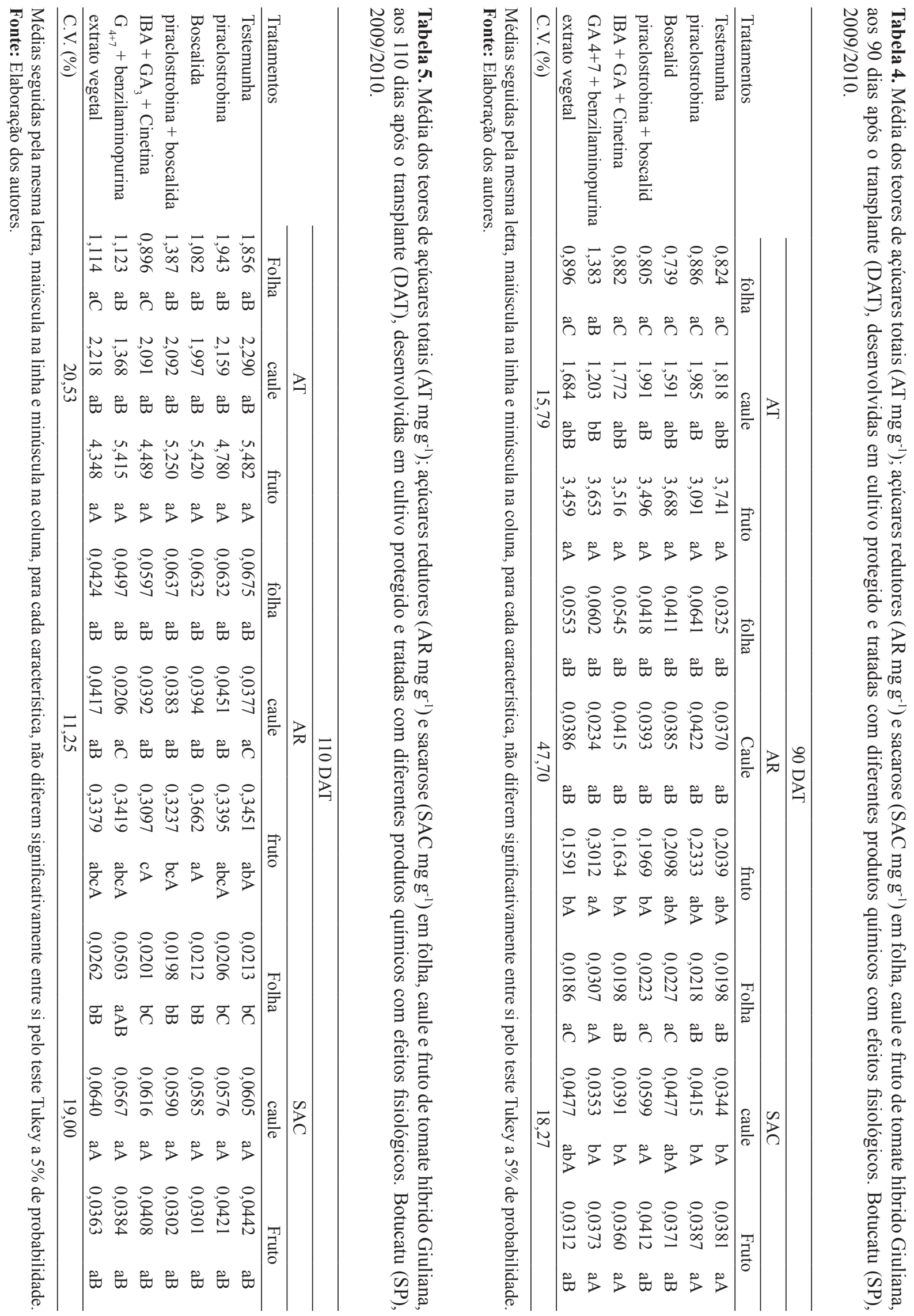




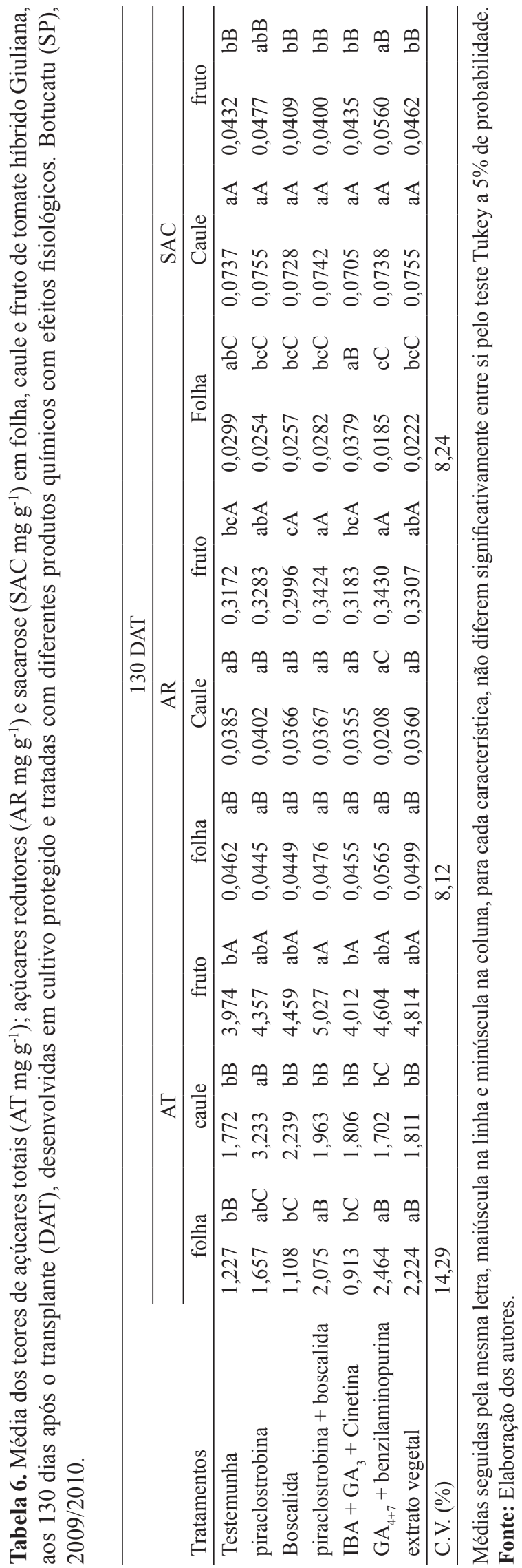

Para Taiz e Zeiger (2011), a capacidade fotossintética da planta depende de reações bioquímicas e da capacidade do tecido foliar para a assimilação fotossintética de $\mathrm{CO}_{2}$ que depende, em grande parte, do conteúdo da enzima ribulose difosfato carboxilase (Rubisco). Além disso, a condutância estomática e a assimilação de $\mathrm{CO}_{2}$ podem estar associadas à presenca das citocininas, as quais estão envolvidas na abertura estomática e na síntese de proteínas da enzima Rubisco (SALISBURY; ROSS, 1994; DAVIES, 2004).

Apesar de não apresentar diferenças nas taxas de trocas gasosas em relação à testemunha, o tratamento com $\mathrm{GA}_{4+7}+$ benzilaminopurina apresentou maior concentração de açúcares totais na folha e de redutores e sacarose nos frutos.

$\mathrm{O}$ uso dos reguladores vegetais pode ter afetado as rotas metabólicas associadas à síntese de proteínas associadas à fotossíntese, proporcionando as diferenças observadas. 
Figura 2. Taxa de assimilação de $\mathrm{CO}_{2}\left(A, \mu \mathrm{mol} \mathrm{CO} \mathrm{m}^{-2} \mathrm{~s}^{-1}\right)$, Transpiração $\left(E\right.$, mmol vapor d'água $\left.\mathrm{m}^{-2} \mathrm{~s}^{-1}\right)$, Condutância estomática $\left(g s, \mathrm{~mol} \mathrm{~m}^{-2} \mathrm{~s}^{-1}\right)$, Eficiência do uso da água $\left(E U A-A / E, \mu \mathrm{mol} \mathrm{CO} \mathrm{C}_{2}\left(\mathrm{mmol} \mathrm{H}_{2} \mathrm{O}\right)\right)$ e Eficiência de carboxilação em folhas de plantas de tomate cv. Giuliana desenvolvidas em cultivo protegido e tratadas com diferentes produtos químicos com efeitos fisiológicos aos 124 DAT, Botucatu (SP), 2009/2010.

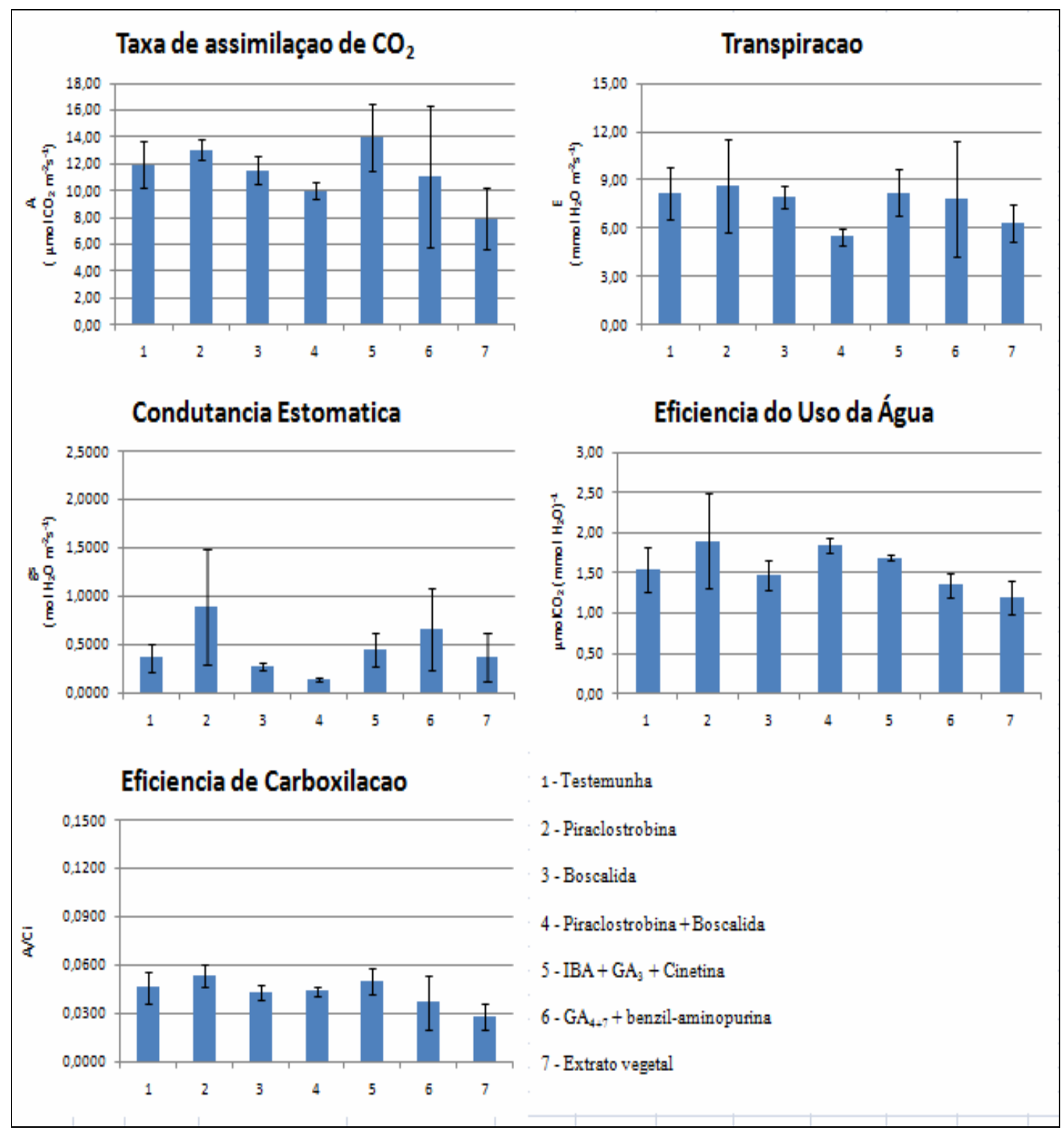

Fonte: Elaboração dos autores.

\section{Conclusão}

A mistura de piraclostrobina + boscalida retardou o amarelecimento das folhas atrasando sua senescência e prolongando a atividade fotossintética. A piraclostrobina e a boscalida aplicados isolados e/ou combinados favoreceram o incremento de carboidratos nas folhas, caules e frutos de tomate 'Giuliana'.

\section{Agradecimentos}

Ao Conselho Nacional de Desenvolvimento Científico e Tecnológico (CNPq) e à Fundação de Amparo à Pesquisa do Estado de São Paulo (FAPESP), pelo financiamento deste projeto de pesquisa. 


\section{Referências}

AMARO, A. C. E. Efeitos fisiológicos de fungicidas no desenvolvimento de plantas de pepino japonês enxertadas e não enxertadas, cultivadas em ambiente protegido. 2011. Dissertação (Mestrado em Horticultura) - Faculdade de Ciências Agronômicas, Universidade Estadual Paulista, Botucatu.

AMARO, A. C. E.; MACEDO, A. C.; SIRTOLI, L. F.; ONO, E. O.; RODRIGUES, J. D. Influência de alguns fungicidas nas trocas gasosas e produção de plantas de pepino japonês enxertadas e não enxertadas, em condições de ambiente protegido. Horticultura Brasileira, Brasilia, v. 27, p. S1964-S1970, 2009. Edição Especial.

AVENOT, H. F.; MICHAILIDES, T. J. Progress in understanding molecular mechanisms and evolution of resistance to succinate dehydrogenase inhibiting (SDHI) fungicides in phytopathogenic fungi. Crop Protection, Guildford, v. 29, n. 7, p. 643-651, 2010.

BENINCASA, M. M. P. Análise de crescimento de plantas: noções básicas. Jaboticabal: Funep, 2003. 41 p.

CAMARGO, M. N.; KLAMT, E.; KAUFFMAN, J. H. Classificação de solos usado em levantamentos pedológicos no Brasil. Boletim Informativo da Sociedade Brasileira do Solo, Campinas, v. 12, n. 1, p. 11-33, 1987.

CASILLAS, J. C.; LONDONO, J.; GUERREIRO, H.; BUITRAGO, L. A. Analisis cuantitativo de la aplicacion de cuatro bioestimulantes em el cultivo rabano (Raphanus sativus L.). Acta Agronomica, Palmira, v. 36, n. 2, p. 185195, 1986.

CASTRO, P. R. C.; VIEIRA, E. L. Aplicação de reguladores vegetais na agricultura tropical. Guaíba: Agropecuária, 2001. $131 \mathrm{p}$.

COLL, J. B.; RODRIGO, G. N.; GARCIA, B. S.; TAMES, R. S. Fisiologia vegetal. Madrid: Ediciones Piramide, 2001. 662 p.

COULOMBE, L. J.; PAQUIN, R. Effects de acide gibberellique sur le metabolisme dês plantes. Canadian Journal of Botany, Birmingham, v. 37, n. 5, p. 897-901, 1959.

DAVIES, P. J. Plant hormones and their roles in plant growth and development. New York: Editor P. J. Davies, 2004. 614 p.

EMPRESA BRASILEIRA DE PESQUISA AGROPECUÁRIA - EMBRAPA. Sistema brasileiro de classificação de solos. 2. ed. Rio de Janeiro, 2006. 306 p.

GARBELINI, R. C. B. da S. Reguladores vegetais na emergência e no desenvolvimento de plantas de macadâmia (Macadamia integrifolia Maiden \& Betche).
2009. Tese (Doutorado em Ciências Biológicas) Instituto de Biociencias de Botucatu, Universidade Estadual Paulista, Botucatu.

HABER, A. H.; TOLBERT, N. E. Photosinthesis in gibberellin-treated leaves. Plant Physiology, Rockville, v. 32, n. 2, p. 152-153, 1957.

HUNTER, J. J.; SKRIVAN, R.; RUFFNER, H. P. Diurnal and seasonal changes in leaves of Vitis vinifera $\mathrm{L}: \mathrm{CO}_{2}$ assimilation rates, sugar levels and sucrolitic enzyme activity. Vitis, Sielbeldingen, v. 33, n. 2, p. 189-195, 1994.

KÖEHLE, H.; GROSSMANN, K.; JABS, T.; GERHARD, M; KAISER, W.; GLAAB, J.; CONRATH, U.; SEEHAUS, K.; HERMS, S. Physiological effects of strobilurin fungicide F 500 on plants. Bioehem Soe Trans, v. 22, p. 65, 1994.

KOHATSU, D. S. Efeito de reguladores vegetais na qualidade de frutos de melão rendilhado. 2007. Dissertação (Mestrado em Agronomia - Horticultura) - Faculdade de Ciências Agronômicas - Universidade Estadual Paulista / UNESP, Botucatu.

LARCHER, W. Ecofisiologia vegetal. Sao Carlos: RiMa, 2006. 550 p.

LEITE, V. M.; ROSOLEM, C. A.; RODRIGUES, J. D. Giberelina e citocinina no crescimento da soja. Scientia Agricola, Piracicaba, v. 60, n. 3, p. 537-541, 2003.

LOPES, M. C.; STRIPARI, P. C. A cultura do tomateiro. In: GOTO, R.; TIVELli, S. W. (Ed.). Produção de hortaliças em ambiente protegido: condições subtropicais. São Paulo: UNESP, 1998. p. 257-319.

MACEDO, A. C. Efeitos fisiológicos de fungicidas no desenvolvimento de plantas de melão rendilhado, cultivadas em ambiente protegido. 2012. Dissertação (Mestrado em Agronomia - Horticultura) - Faculdade de Ciências Agronômicas, Universidade Estadual Paulista, Botucatu.

MARTINS, M. B. G.; CASTRO, P. R. C. Aspectos morfoanatomicos de frutos de tomateiro cultivar Angela gigante, submetidos a tratamentos com reguladores vegetais. Bragantia, Campinas, v. 57, n. 2, p. 225-236, 1997.

MATSUMOTO, K. Giberelinas. In: CID, L. P. B. Introdução aos hormônios vegetais. Brasília: Embrapa Recursos Geneticos e Biotecnologia, 2000. p. 83-105.

MILLER, G. L. Use of dinitrosalicylic and reagent for determination of reducing sugar. Analytical Chemistry, v. 31, n. 3, p. 426-428, 1959. 
MORRIS, D. L. Quantitative determination os carbohydrates with Derwood's anthrone reagent. Science, Washington, v. 5, n. 107, p. 254- 255, 1948.

PALliOTTI, A.; CARTECHIN, A. Developmental changes in gas exchange activity in flowers, berries and trendils of fieldgrown Cabernet Sauvignon. American Journal of Enology and Viticulture, Davis, v. 54, n. 4, p. 317-323, 2001.

PASSOS, L. P. Métodos analíticos e laboratoriais em fisiologia vegetal. Coronel Pacheco: EMBRAPA CNPGL, 1996. 223 p.

PEEL, M. C.; FINLAYSON, B. L.; MCMAHON, T. A. Updated world map of the Köppen-Geiger climate classification. Hydrology and Earth System Sciences, v. 11, p. 1633-1644, 2007.

POPOV, E. G.; TALANOV, A. V.; KURETS, V. K.; DROZDOV, S. N. Effect of temperature on diurnal changes in $\mathrm{CO}_{2}$ Exchange in intact cucumber plants. Russian Journal of Plant Physiology, v. 50, n. 2, p. 178182, 2003.

RAMOS, A. R. P. Produtos de efeitos fisiológicos no desenvolvimento de plantas de tomate 'Giuliana', na produção e pós-colheita de fruto. 2013. Tese (Doutorado em Agronomia - Horticultura) - Faculdade de Ciências Agronômicas, Universidade Estadual Paulista, Botucatu.

ROITSCH, T.; BALIBREA, M. E.; HOFMANN, M.; PROELS, R.; SINHA, A. K. Extracellular invertases: metabolic enzyme and metabolic protein. Journal of Experimental Botany, Lancaster, v. 54, n. 382, p. 513524, 2003.

SALISBURY, F. B.; ROSS, C. W. Fisiologia vegetal. Tradução Velazquez, V. G. Mexico: Iberoamerica, 1994. $759 \mathrm{p}$.
SOUZA LEÃO, P. C. de; SILVA, D. J.; SILVA, E. G. da. Efeito do ácido giberélico, do bioestimulante cropset e do anelamento na produção e na qualidade da uva 'Thompson Seedless' no vale do São Francisco. Revista Brasrasileira de Fruticultura, Jaboticabal, v. 27, n. 3, p. 418-421, dez. 2005.

TAIZ, L.; ZEIGER, E. Fisiologia vegetal. 5. ed. Porto Alegre: Artmed, 2011. 690 p.

TYMOWSKA-LALANNE, Z.; KREIS, M. The plant invertases: physiology. biochemistry and molecular biology. Advances in Botanical Research, Cambridge, v. 28, n. 1, p. 71-117, 1998.

VENÂNCIO, W. S.; RODRIGUES, M. A. T.; BEGLIOMINI, E.; SOUZA, N. L. de. Physiological effects of strobilurin fungicides on plants. Publicatio UEPG Ciências Exatas e da Terra, Ciências Agrárias e Engenharia, Ponta Grossa, v. 9, n. 3, p. 59-68, dez. 2003.

VON CAEMMERER, S.; FARQUHAR, G. D. Some relationships between the biochemistry of photosynthesis and the gas exchange of leaves. Planta, Berlin, v. 153, n. 4, p. 376-387, 1981.

YEMM, E. W.; WILLIS, A. J. The estimation of carbohydrates in plant extracts by anthrone. Biochemical Journal, Londres, v. 57, n. 3, p. 508-514, 1954.

YPEMA, H. L.; GOLD, R. E. Kresoxym-methyl modification of a naturally occurring compound to produce a new fungicide. Plant Disease, Saint Paul, v. 83, n. 1, p. 4-19, 1999. 